\title{
A socio-ecological perspective of urban green networks: the Stockholm case
}

\author{
$\mathrm{Na} \mathrm{Xiu}^{1}{ }^{1}$ - Maria Ignatieva ${ }^{1}$ - Cecil Konijnendijk van den Bosch $^{2} \cdot$ Yongyu Chai $^{3}$. \\ Fei Wang ${ }^{3} \cdot$ Tengfei Cui $^{4} \cdot$ Fengping Yang ${ }^{1}$
}

Published online: 27 January 2017

(C) The Author(s) 2017. This article is published with open access at Springerlink.com

\begin{abstract}
Landscape fragmentation threatens habitats, biodiversity and other ecosystem services. In tackling this threat, the dynamic processes of social-ecological systems should be recognised and understood. Although network analysis based on graph theory has been recognised as an efficient way of spatially understanding landscape or habitat connectivity, only few studies have offered specific approaches or suggestions for integrating detailed social-ecological values into geographical distributions. As a contribution to bridging this gap, this paper introduces a social-ecological network model for the issue of landscape or habitat fragmentation applied to the case of Stockholm, Sweden. Graph theory was used in combination with sociotope and biotope maps for simple visualisation of network situations in two-dimensional maps. The European crested tit (Lophophanes cristatus), European common toad (Bufo bufo) and human beings were selected as indicator species, based on a landscape ecology analysis in Stockholm Municipality in 2009. Slope, land use and human disturbance maps were assessed in order to decide cost values of travelling from node to node. Lease-cost-path accumulation was used to create ideal reference maps of green networks. Three separate maps were then developed for suggesting
\end{abstract}

Na Xiu

na.xiu@slu.se

1 Department of Urban and Rural Development, Swedish Univeristy of Agricultural Sciences, P.O Box 7012, 75007 Uppsala, SE, Sweden

2 Department of Forest Resources Management, University of British Columbia, Vancouver, Canada

3 Northwest Institute of Forest Inventory, Planning and Design, State Forestry Administration, Xi' an 710048, People's Republic of China

4 Department of Geography and Planning, University of Saskatchewan, S7N 5C8, Saskatoon, SK, Canada efficient routes for three indicators in city scale that mainly connect from the Royal National City Park to the other parts of the city. The model in Hjorthagen neighbourhood to highlight two practical paths that link this fragmented community to its neighbouring park areas. Findings make it possible to address two scales of network improvement strategies, namely first for the city-scale green network that connects geographical habitats (nodes) and the regional green wedges of the city, and the second that of neighbourhood links between habitats in detailed layers of green networks. Strategic improvement potentials are presented based on ideal reference maps of green networks correspondingly.

Keywords Graph theory $\cdot$ Least-cost-path $\cdot$ Species indicators $\cdot$ Structural connections $\cdot$ Urban green networks

\section{Introduction}

Green and blue spaces, together with other land use changes are determining factors of habitat fragmentation, biodiversity loss and decline of ecosystem services in urbanized areas (Adriaensen et al. 2003; Collinge 1996; Kong et al. 2010; Teng et al. 2011; Zetterberg et al. 2010). Furthermore, the amount of green space and its distribution, and the ease of access to such space are key contributors to cultural ecosystem services (e.g. those related to recreation, health and wellbeing, culture) in urban environments as well (Barbosa et al. 2007; Cook and Lier 1994). Although some promising green space planning concepts and approaches have emerged during recent decades, green and blue spaces often fall victim to modern urban planning and design (Kong and Nakagoshi 2006). One of the latter's failures relates to experts examining ecological systems or social systems, but not considering integration of both in great detail (Xiu et al. 2016). Moreover, the major 
challenge for current cities is to maintain both biological diversity and the recreational values in parallel to urban development (Löfvenhaft et al. 2004). Green and blue spaces provide three categories of benefits simultaneously: socio-cultural, ecological and economic. The process of integrating these is dynamic, since for example, excessive social activities are thought to disrupt ecological functions of green-blue spaces, while moderate social activities can go well together with ecological functions (Chapin et al. 2000). Good performance of social and ecological systems can also result in economic impacts, as reflected in higher house prices (Luttik 2000), in higher land and property values, tourism enhancement, labour market employment, productivity and so forth (McPherson 1992).

In an attempt to tackle the issue of habitat fragmentation (with habitat here not only relating to flora and fauna, but also to human beings), landscape connectivity is regarded as an important measure (Kong et al. 2010; Zetterberg 2011; Forman and Godron 1986). The concept of landscape connectivity has been defined as "the degree to which absolute isolation is prevented by landscape elements which allow organisms to move among patches" by Taylor et al. (1993). A higher degree of flow of organisms is normally desired except for the case of diseases or invasive species. Functions of connectivity are achieved through structural composition and spatial configuration of elements, such as patches and corridors (Merriam 1984; Taylor et al. 1993; Zetterberg 2011). A graph-theoretic approach (graph theory is the theory of graphs application through mathematical algorithms) therefore can provide an operable way of framing and evaluating features of connectivity (Bunn et al. 2000; Kong et al. 2010; Minor and Urban 2008; Mörtberg et al. 2007a; Urban and Keitt 2001). Graph theory is well recognised within geography, information technology and computer science. Algorithms and data structures can be easily adapted at the landscape level, as shown by Bunn et al. (2000) and as demonstrated within ecology by Urban and Keitt (2001). The graph comprise a network that is always represented through a graph drawing of nodes $(\mathrm{N})$ and links $(\mathrm{L})$ (Aldous and Wilson 2000), where a node represents a habitat and a link is the dispersal in between. Based on this visualization, spatially and geographically defined land-cover grids of fragmented regions can be transformed into two-dimensional graphs for further analysis - for example in a least-cost modelling approach.

The least-cost-path (LCP) modelling approach, referred as cost-distance modelling, uses algorithms for deciding the shortest effective distance between nodes on a raster (Adriaensen et al. 2003). Paths calculated from LCP models are those most cost-saving for targeted users travel from one site to another. Different from Euclidean distance, LCP paths are established from minimal theoretical cumulative-cost. They follow a bypass as a result of preferred habitats in order to minimise exposure to low quality habitats, and facilitate movement (Teng et al. 2011). For the purpose of calculating the cumulative cost in a proper way, many factors need to be considered, including slope, ground cover, human disturbance, etc. Moreover, there is not only one user in a network, as many species share the use of a common network in urban areas. It is unrealistic to analyse all species, and thus specific species need to be selected in accordance with targeted purposes, such as focal species, red-list endangered or vulnerable ones with priority needs.

Although network analysis has been established as a promising approach to explore landscape connectivity for counteracting fragmentation, little research has incorporated frameworks aimed at a wider sense of operation. Hence in this paper, the concept of 'green networks' is expanded into a concrete analytical framework for studying green and blue linkages, as well as social and ecological connections and integrations. We selected Stockholm, capital city of Sweden and green capital of Europe 2010, as an example of a city with ample urban green spaces, but also with challenges in terms of green space fragmentation, such as the green space loss since 1998 according to the report of Stockholm City Habitats (Stockholm Stad 2012). The main research questions addressed in this paper are: how can the green network concept provide a comprehensive framework for analysing landscape and habitat fragmentation, and how can current city green-blue spaces planning and design benefit from it.

\section{Theoretical frame and methods}

According to the research questions above, this paper presents two theoretical and methodological components. The first of these comprises the theoretical background and framework of green networks for green-blue connections and social-ecological integration. Next, the specific methodology for testing the framework in a specific city - Stockholm, Sweden - is introduced. Figure 1 shows the overall process of framework. The detailed methodology is subsequently described in the sections Green networks to Cost-distance/ least-cost-path analysis.

\section{Visualized green networks based on graph/network theory}

The term 'green networks' refers to green structure as well as surface and ground water occurring in the urban landscape that link to the surrounding landscapes. Green networks are defined as a set of networks with social and ecological functions, linked into a spatially coherent entity through flows of organisms, and interacting with the landscape matrix (Xiu et al. 2016). These networks represent an integration of three categories of networks in practice: river (or blue) network (serving as edges), green space network (serving as nodes) and transport greening network (greenery along the roads, 


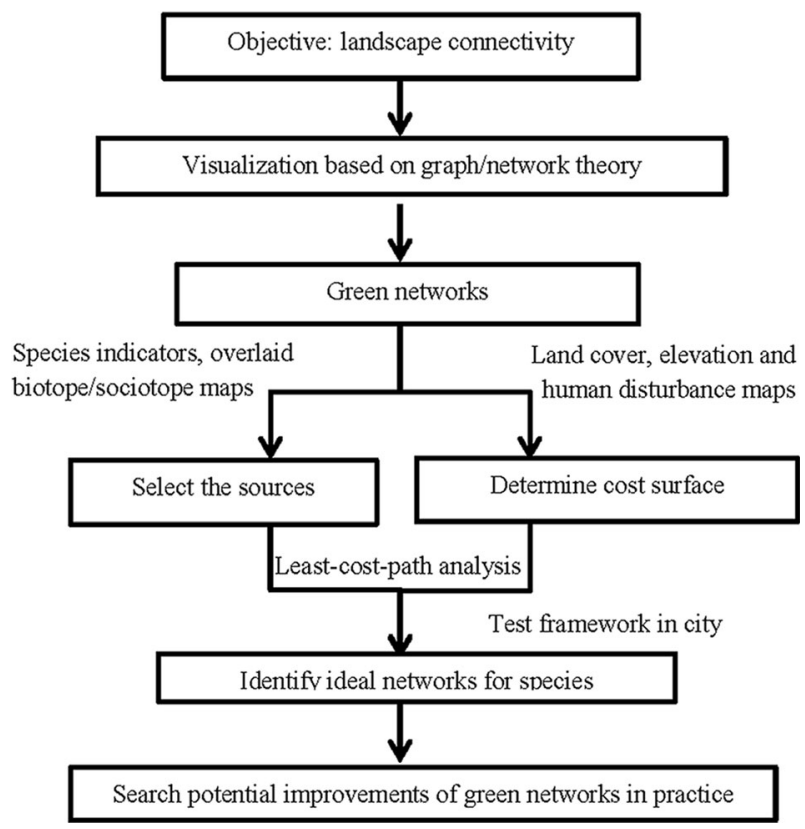

Fig. 1 The paper's analytical framework of green networks and its implementation into practice

served as corridors and edges as well). Green-blue spaces in an urban environment are layered for portray potential habitat patches and dispersal links. The ultimate aim is to combine these three networks into an overall 'green network' (serving as matrix and network) (Fig. 2). Both from a social and ecological perspective, the three networks play an important role since they provide habitats where flora and fauna live, move, reproduce, etc., and where human beings move and recreate. Furthermore, greenblue connections between the three networks provide crucially interactive habitats and stepping stones for wildlife and preferred places for humans.

Applying graph theory to green-blue space planning, habitat patches are linked by connectivity zones and species dispersal, which compose a network in reality. Habitat patches are normally those varied scaled plant communities in green spaces (Cook 2002), road greenery and water ways serve as linkages (although sometimes waterways can be great barriers to habitat movement) (Xiu et al. 2016). The most common issue in graph theory is about network flow between nodes or the cost flow. It deals with shortest or maximum path of moving within a network for dedicated users. Since Urban and Keitt (2001) introduced graph theory at the landscape level it has been commonly recognised that habitat patches can be represented as nodes that are connected to some extent by edges (Minor and Urban 2008; Urban and Keitt 2001; Zetterberg 2011; Zhang and Wang 2006). Between nodes, edges provide the ecological flux for example through genetic movements, species migration, etc. Then landscape topology can be visualised as a graphed network of patches linked via connectivity zones for propagule dispersal or material flow (Fig. 3).

\section{Sources selection based on species indicators and sociotope/biotope maps}

After geographical selection and visualisation of green networks, the question emerges how to choose crucial node sources (habitat locations) when considering both sociological and ecological functions, which means selecting habitats that can work for both wildlife shelters and human recreation. As widely known for the case of complex networks, the structure is different in terms of different users. For example, one person's social network may be quite different from another person's, although they may work or live in the same area. One species' dispersal network differs from another species, although they may mutually related and dependent. In the analysis of ecosystems and their management, specific species are often used as indicators since they are believed to indicate fluctuations of other species (Simberloff 1998). These specific species are considered as targets and their habitat requirements are used to analyse the habitat criteria of landscape support (Billeter et al. 2008). This approach also respond to a reality in which it is unrealistic to monitor and manage every species in landscape connectivity research. Hence, it is necessary to select one or several species as representative indicators of habitats and even of the entire community ecosystem (Simberloff 1998). A series of approaches and criteria have emerged, such as selecting umbrella, flagship, keystone or focal species in ecological perspective (Caro 2010; Zetterberg 2011). However, in this paper we argue that in addition to ecological functions, indicator species play a significant role in expressing physical contexts of landscape, such as land uses, or different layers of green networks that discussed above (green or blue spaces). In order for indicator species to gain acceptance within planning, design and decision making, these species should also provide some information on social values. Therefore, species selection should take one extremely important species into consideration - human beings as the issue of landscape fragmentation is not only about ecological segmentation for wildlife but also very much about humans. Even more crucially, people are the driving forces behind landscape fragmentation and they will continue to influence how this issue is being identified, now and in the future (Spangenberg 2007).

Therefore, we use two types of geographical reference mapping analysing and showing wildlife and human activities: biotope mapping and sociotope mapping. Biotope was first defined in Germany in the 1970s as an area providing a living place for a specific assemblage of plants and animals (Sukopp and Weiler 1988). Biotope mapping is the identification and specification of biotopes in maps. Two methods of biotope mapping exist: selective biotope mapping for certain 
Fig. 2 Concept map of green networks

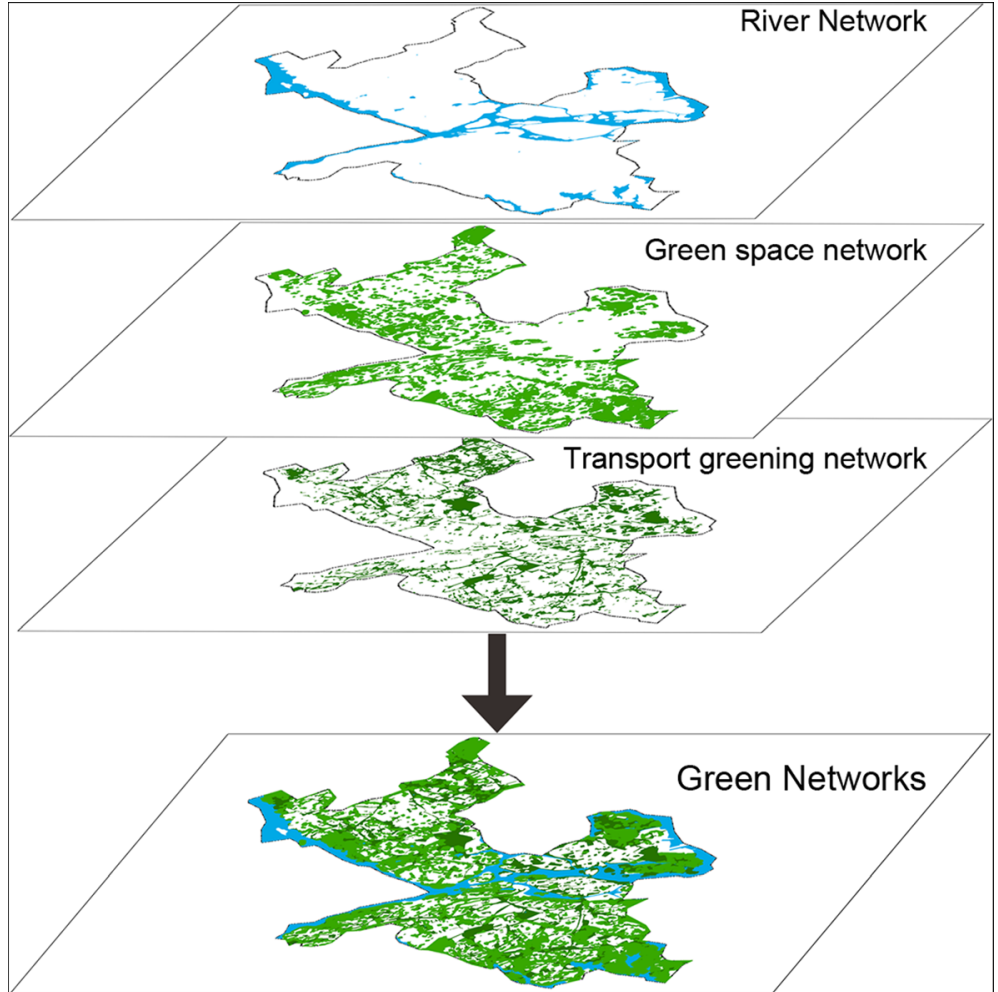

biotopes and dedicated species worthy of protection, and comprehensive mapping for all biotopes in the city or research areas (Sukopp and Weiler 1988). Nowadays many cities have created comprehensive biotope maps according to own ecological contexts, aimed at marking biotopes and maintaining biodiversity in urbanised areas (Qiu et al. 2010). The concept of "sociotope" has emerged in Sweden by adapting the biotope concept to a social value context within city planning, assessments and decision-making. Sociotope mapping thus focuses on the social values of open space, related to the frequent use of an area by citizens, their opinions and preferences, and is measured by public participation through interviews and questionnaires answered by urban planners and the general public (Ståhle 2006). Sociotope maps are now included in many Swedish municipal planning processes, for example in Stockholm, Uppsala, Malmö and Gothenburg. It has proved to be a useful tool to visualise social values of landscapes.
This paper focuses on those human recreation places that are most frequently used in cities, using procedure similar to that for selecting important biotopes in cities. Locations of plant communities for species' breeding, gene migration, winter-summer hibernation etc. were chosen as ecological habitats. Overlaid valuable biotopes and sociotope locations are subsequently merged. The geographical location of certain points coincided, which would suggest that they are functional from both a sociotope and biotope perspective. These dualimportant habitats can fulfil both human recreational and ecological values for wildlife in green networks. Although these two functions almost always conflict in cities, identifying locations that can fulfil both values is still a holistic perspective and to balance different interests of humans and other life forms in urban environments (Xiu et al. 2016). It has to be noted that, however, based on different purposes of planning and design, species and valuable patches may differ as well, depending on the priorities of the specific city context.
Fig. 3 An example of a graphed network (a) and its correspondingly physical extent in real landscape topology (b). Nodes are normally patches with different purposes, such as species habitats, stepping stones. Edges are multiple connection zones between patches
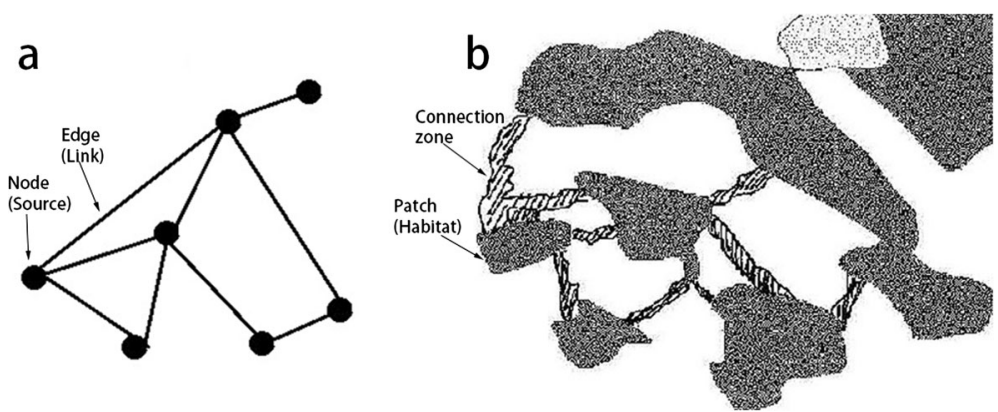


\section{Cost-distance/least-cost-path analysis}

The optimum edges between nodes in a network are those that minimise risks of crossing low-qualified areas and facilitate species dispersal (Teng et al. 2011). When searching for effective edges, impedance cost created by the mosaics of land uses from one node to another need to be considered. Cost distance is the main measure to decide costs in terms of different landscapes. Among the determining factors for costs are land cover, human disturbance, and slope of landscape. The least-cost-path (LCP) uses a raster-based algorithm to calculate the minimal route of theoretical cumulative-cost (Adriaensen et al. 2003). A number of tools are provided in GIS software for least-cost-path analysis, for example the tools "cost-distance" and "least-cost-path" in ArcGIS Spatial Analyst (ESRI 2015).

\section{Framework test in Stockholm, Sweden}

Stockholm, capital city of Sweden, is located in northern Europe. Stockholm was awarded the European Union's 'Green Capital Award' in 2010 and is considered good example of green space planning. However, Stockholm is also a fragmented city due to its topography, continued urban development and from an ecological perspective (Löfvenhaft et al. 2004). Based on the Stockholm City Habitats report published by Stockholm Municipality in 2012, Stockholm has been facing challenges in terms of biodiversity loss, green space loss and conflicts between green/blue and grey spaces since 1998 .

The test area for this study, with an area of $215 \mathrm{~km}^{2}$, covers the City of Stockholm with its approximately 900,000 residents (Fig. 4). The city of Stockholm comprises of 14 islands of districts on the coast of Lake Mälaren and Baltic Sea. It includes narrow valleys with lakes, remnant forests hills
(50-90 $\mathrm{m}$ in altitude), grassland and agricultural fields, constructed buildings and roads.

Although green-blue spaces (including parks and other green zones) account for $57 \%$ of Stockholm's total land area, this is a steep decrease from the past. From 1998 to 2009 the reduction of green-blue spaces in Stockholm has been 1 . $92 \mathrm{~km}^{2}$, leading to a corresponding increase of impermeable surfaces such as roads and buildings. This trend is going to continue because of densification and construction in the city. Stockholm is one of the five fastest growing cities in Europe according to Stockholm Municipality. By 2022 the population will reach 1 million which requires continuous infrastructure development and which will make conflicts between different land uses, especially green-blue and grey spaces, even more prevalent. The city is and will continue to have more isolated and fragmented landscapes. Thus we test the green network framework in Stockholm to see how a socio-ecological framework of green networks can benefit current green and blue space planning, and how green/blue spaces in a fragmented city can be connected as a functional network and can eventually be used in practical work of urban planners.

\section{Data collection and ecological-social parameters}

The test used several geographical databases with complete geographic coverage of the study areal, including GSD Swedish vector maps $(1: 1000,000)$ of the General Map, Land cover map, Property map and Topographic pap (1:50,000), Swedish raster elevation map with $50 \mathrm{~m}$ resolution from the National Land survey of Sweden 2014 and Population vector map (until December 31st, 2013) from Statistics Sweden. GSD vector maps are based on multispectral satellite data from Landsat TM with $30 \times 30 \mathrm{~m}$ geometric resolution with plane coordinate system SWEREF 99 TM.
Fig. 4 Stockholm's location in Sweden (a) and its land use map (b)

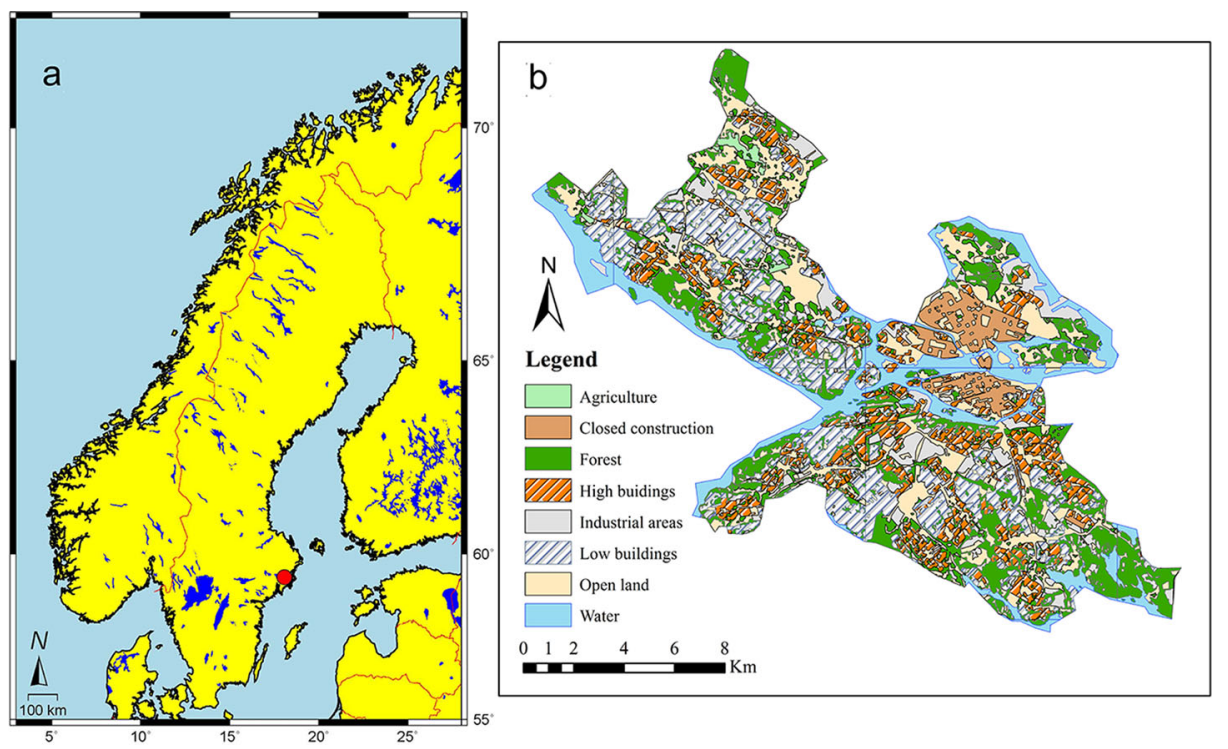


These maps and field surveys were used for creating land use maps and the concept map of the green network (river, road greenery and green space layers). The biotope and the vegetation databases used XML Extensible Markup Language format that are from Open Stockholm Portal of Stockholm City and published in 2009. FME (Safe Software) was then used to integrate records for spatial shapefile that can be coordinated in 2015 ESRI's ArcMap 10.3.1. The digital sociotope map was prepared by the City of Stockholm; initiallyin 2004 and updated in 2009 with help of Alexander Ståhle. Raster elevation map and population map were used for cost value determination that we introduced in this paper and this is illustrated specifically in subchapter Cost distance determination and least-cost-path analysis.

In addition, scientific literature in combination with reports mainly from Stockholm City provided material for the study. The latter included e.g. the report of Stockholm City Habitats published in 2012, Landscape Ecological Analysis in City of Stockholm for oak trees and coniferous forest (Mörtberg et al. 2007b), Landscape Ecology Analysis in City of Stockholm for method development in amphibians (Mörtberg et al. 2007a), and the Stockholm Species Database by Stockholm Municipality (2005). An assessment of these reports and expert opinions were used for identifying representative parameters e.g. suitable habitats considering ecological and social values and cost values.

\section{Sources/destination selection (species indicators and biotope/sociotope mapping)}

European crested tit (Lophophanes cristatus), European common toad (Bufo bufo) and human being were selected in this study as three species indicators also referred in the reports of Landscape Ecology Analysis by City of Stockholm (Mörtberg et al. 2007a, b). All three are identified as focal species in these reports. Some species are due to their large habitat and facilitated connectivity demands impacted more than those with lower demands from landscape ecology's perspective (Hoffmeister et al. 2005). Therefore species such as birds and small amphibian should be prioritized. Birds and amphibians are not only largely related to the valuable natural types in Stockholm, such as wetlands, bogs, deciduous forests and coniferous forests (especially the oak trees), but also to the surrounding urban landscape. All amphibian species in the city of Stockholm are listed as worthy of protection since they are highly threatened by urban landscape (Gothnier et al. 1999). The European common toad is the second most common species in Stockholm. It is less sensitive to desiccation and obstacles such as lower walls, railways tracks and blocking vegetation, and can move long distances in drier areas. Although the crested tit is not considered to be an endangered species in Stockholm, there are signs of its possible decline as a result of vulnerability to urbanization. On another hand, in order to highlight values of three green network layers, species indicators should be those who can be suitable representatives of different layers. In Sweden the $\mathrm{n}$ crested tit prefers coniferous, hardwood forests and other green spaces. The European common toad is typical for bogs, wetlands and several other blue spaces (although capable to live in terrestrial areas as well). These species provide important social and educational values as well with the European common tit being bird perderred by people and welcomed in most neighbourhoods. Both the crested tit and common toad also offer great educational values, for example for school children (Mörtberg et al. 2007a, b).

In terms of habitat selection, Cook (2002) noted that the contribution of land cover and vegetation cover can be a surrogate for habitat value. References maps of sociotopes and biotopes combined with scientific literatures and experts assessments were used for building a set of criteria to select node patches, namely consider that: 1) the land patches which can be potential habitats in biotope map for crested tit and common toad, and commonly used habitats in sociotope map for human recreation; 2) large areas of habitats suffer more acutely from landscape fragmentation, so we selected larger habitats as high priority of connection (he minimum area of patches was $1 \mathrm{ha}$ ); 3) the patches' central point should be located inside of area because irregular polygons of habitats may centre outside the graphs. Therefore we selected 771 patches in sociotope and 1681 patches in biotope maps.

Patches were transferred from each source map into analytical central points and the two maps were merged into one (Fig. 5a). Some of the patches on the two maps overlaid each other which demonstrates that those habitats serve both ecological and social values for indicator's species and also for general wildlife, as well as people's recreation in Stockholm. We extracted points with such values and selected them as potential network nodes to build up and analyse green networks. We used $100 \mathrm{~m}$ as a clip data correction since a position deviation may occur when converting from irregular polygon patches to the central points. Following these steps, we selected 596 nodes in the whole city (Fig. 5b). The nodes represent the potential ecological and social demanding areas for wildlife and humans' movement and contact with nature.

\section{Cost distance determination and least-cost-path analysis}

Scientific publications and expertise assessments were used for determination of cost values in a range of relative numbers by summarising important factors (Adriaensen et al. 2003; Rayfield et al. 2010; Zetterberg et al. 2010; Kong et al. 2010; Teng et al. 2011). High numbers represent high cost of travelling and low suitability for dispersal of organisms. In this study we considered the following factors: land cover $\left(\mathrm{C}_{1}\right)$, human disturbance $\left(\mathrm{C}_{\mathrm{d}}\right)$ and topography slope $\left(\mathrm{C}_{\mathrm{s}}\right)$. Land cover $\left(\mathrm{C}_{1}\right)$ for the three indicator species was estimated in 
Fig. 5 a Biotope and sociotope points for representing valuable habitats and (b) 596 crucial habitats in Stockholm

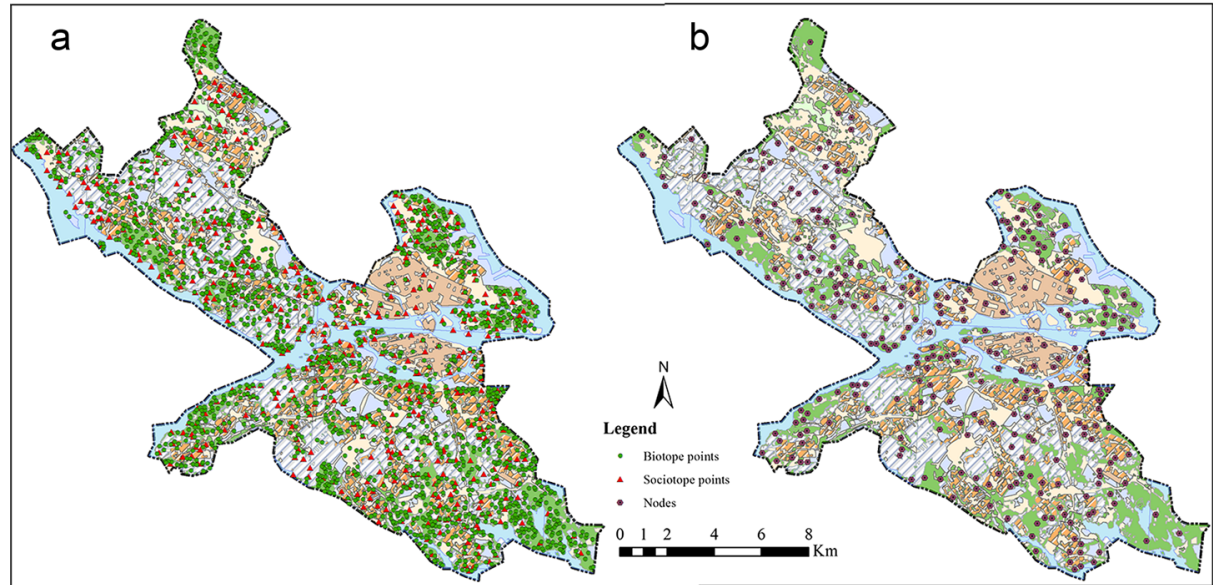

accordance with different land use type (from built areas to forested lands) (Table 1). We used population density to predict human disturbance $\left(\mathrm{C}_{\mathrm{d}}\right)$ assuming that anthropogenic impedance directly relates to human density and activity. Slope $\left(\mathrm{C}_{\mathrm{s}}\right)$ is an important factor in crossing between nodes and differs depend on species, indicating the relative costs of a terrain's surface represented by DEM (Digital Elevation Model).

$\mathrm{C}_{1}$ includes 10 categories of land use types and we decided its range as $1-1000$ for crested tit and 1-10,000 for common toad to highlight and distinguish the degree of impedance to different species; normally amphibians need greater efforts to
Table 1 Cost values and weights for land cover, human disturbance and slope variables for LCP analysis in the test of Stockholm

\begin{tabular}{|c|c|c|c|c|c|c|c|}
\hline \multirow[t]{2}{*}{ Variable } & \multirow[t]{2}{*}{ Attribute } & \multicolumn{2}{|c|}{ Crested tit } & \multicolumn{2}{|c|}{ Common toad } & \multicolumn{2}{|c|}{ Human } \\
\hline & & Costs & Weight & Costs & Weight & Costs & Weight \\
\hline \multirow[t]{10}{*}{ Land cover $\left(\mathrm{C}_{1}\right)$} & Agriculture & 50 & \multirow[t]{10}{*}{0.5} & 100 & \multirow[t]{10}{*}{0.4} & 7 & \multirow[t]{10}{*}{0.7} \\
\hline & Coniferous/mixed forest & 1 & & 1 & & 9 & \\
\hline & Deciduous forest & 10 & & 10 & & 8 & \\
\hline & Other open land $*^{l}$ & 400 & & 3000 & & 1 & \\
\hline & Water & 1000 & & 10,000 & & 10 & \\
\hline & Closed construction $*^{2}$ & 300 & & 7000 & & 6 & \\
\hline & Low building & 200 & & 1000 & & 3 & \\
\hline & High building & 500 & & 8500 & & 4 & \\
\hline & Recreational building & 600 & & 7500 & & 2 & \\
\hline & Industrial area & 800 & & 8000 & & 5 & \\
\hline Human disturbance & $<20$ people/ha & 1 & 0.4 & 1 & 0.4 & 1 & 0.15 \\
\hline$\left(\mathrm{C}_{\mathrm{d}}\right)$ & $20-40$ & 10 & & 150 & & 2 & \\
\hline & $41-60$ & 20 & & 300 & & 4 & \\
\hline & $61-90$ & 45 & & 500 & & 6 & \\
\hline & $91-120$ & 70 & & 700 & & 8 & \\
\hline & $121-180$ & 85 & & 900 & & 9 & \\
\hline & $>180$ & 100 & & 1000 & & 10 & \\
\hline Slope $\left(C_{\mathrm{s}}\right)$ & $0-10 \mathrm{~m}$ & 1 & 0.1 & 1 & 0.2 & 1 & 0.15 \\
\hline & $11-20$ & 30 & & 300 & & 3 & \\
\hline & $21-30$ & 50 & & 500 & & 5 & \\
\hline & $31-45$ & 70 & & 700 & & 7 & \\
\hline & $45-60$ & 90 & & 900 & & 9 & \\
\hline & $60-90$ & 100 & & 1000 & & 10 & \\
\hline
\end{tabular}

*1 Linear roads and plazas between sidewalks and curbs or islands, usually with buffer green spaces next to them $*^{2}$ In the old town of Stockholm, areas of historical importance are prohibited from any construction 
cross different landscapes than birds and humans. $\mathrm{C}_{\mathrm{d}}$ and $\mathrm{C}_{\mathrm{s}}$ include 7 and 5 attributes based on level of human population density and natural elevation, respectively. Their costs were decided to fall within the range of 1-100 to indicate the corresponding contribution in organism movement. Then attributes in different cost types were weighted and overlaid to calculate the final costs in a raster format that would be accumulated in further LCP analysis. Table 1 shows the summarized cost values and weights assigned for LCP. Based on network nodes and recalculated dispersal costs, least-costpath analysis showed to be a convenient tool using ArcGIS to calculate the most effective connection between nodes. Then three optimized network graphs because of different cost values were created correspondingly.

\section{Exploring the improvement potential of current green-blue spaces from two levels}

From a regional level, Stockholm is one of the greenest cities in Europe as a result of its 10 Green Wedges plan which brings a variety of benefits including recreation, biodiversity, health, culture, etc. (Regional Development Plan for the Stockholm, RUFS 2010). These long-term regional and municipal wedges are large, contiguous green spaces adjacent to buildings and other developed areas. Although several of Stockholm's wedges continue nearly into the city, a growing number of green spaces in the city itself have been, and continue to be transformed impervious surfaces occupied by buildings and roads due to ongoing urban development and densification. This is the case particularly for green areas outside of the green wedges (Stockholm Stad 2012). For example, from 1998 to 2009 the City of Stockholm lost $0.9 \%$ of green spaces in total, while it gained the same percentage of hard surface (Fig. 6). Part of these losses also happened within the green wedges. Therefore, a more detailed green network plan on the city level combined with the existing Green Wedges plan at the regional level is deemed necessary for guiding city development without impacting ecosystems and ecosystem services.

In order to manage overall network calculation in a practical way, we categorized the LCP analysis at two levels - city and neighbourhood. For the city scale fewer nodes and links need to be visualized. For local scale detailed nodes and links should be identified in order to show the role of the specific part of the green network in Stockholm. Thus it can also be a useful tool for developing practical recommendations for urban planning. This intermediate method fills the gap of overall and detailed representation and uses the same methodology. The urban green network is similar to any other type of landscape, representing a complex system comprised by a variety of smaller elements which are complex systems as well. Green network analysis can be regarded as "nesting iteration between different scales" (Zetterberg et al. 2010). This implies that the urban green network operates at a bigger scale system that is comprised by the numerous site-specific green networks. Planning and design approaches implemented at a larger scale of urban green networks affect network in specific sites, and vice versa.

In the following green network analysis at the city scale, the graph was based on the 596 potential sites (see section Source/Destination selection), which are still too many to be effectively visualized and analysed. Some of the points among those basement points are quite close geographically. Further selection and aggregation of important patches was based on merging points in radius of $500 \mathrm{~m}$. This also corresponded with the home range of $90 \%$ of the common toad individuals, which are capable to move in the shortest distance among the entire indicators (crested tit and humans). These toads are migrating a distance of less than $1 \mathrm{~km}$ during one year (Zetterberg et al. 2010). As a result we assumed that $500 \mathrm{~m}$ is the effective migration radius of one patch in the city scale. Then points that have its neighbours within a diameter less than $500 \mathrm{~m}$ can be merged and selected by one point. Fiftynine points were then selected eventually as critical nodes among 596 habitats in Stockholm city. Eliminating points does not mean that these are less important in this research, as they could provide the opportunity for zooming in at the local level for more detailed analysis.

City-scaled green network analysis can be seen as a way to identify the important structures within the city, by selecting the most critical nodes and links. These critical patches and connectivity zones should receive higher priority in a city during urban planning and design phase. Density Analysis in ArcGIS was employed to distinguish different priority of planning. Three simple classed using standard deviation $(N=2.5)$ were applied to show different levels of density. Higher density paths demonstrate higher need of planning and design at a city level. Then analysis could turn to a smaller scale aiming to see how specific improvements can be achieved in order to improve network functions in local and city scales. Rerunning the green networks model containing all detailed sources in a neighbourhood level was done to suggest efficient routes that can connect important habitats and imply the potential of linking green-blue spaces in larger scale ultimately. For this paper we selected the Hjorthagen city district which is located in the north-eastern part of Stockholm as a local scale example to show how green network can be operationalised. Hjorthagen is particularly important since it contains the Stockholm Deer Park (Djurgården) as a big and important habitat (part of Green Wedge). The Deer Park is one of the 596 habitat patches that provide both ecological and social values for selected species. It is part of the National City Park, but the park is somewhat isolated from neighbouring areas because of lack of connections in the green network. This area is suffering from the densification trend in Stockholm (and elsewhere in Sweden) in which less dense city form is replaced by a densification and a 
Fig. 6 Loss of green spaces and 10 Green Wedges in the city of Stockholm (redrawn from

Stockholm Stad 2012)

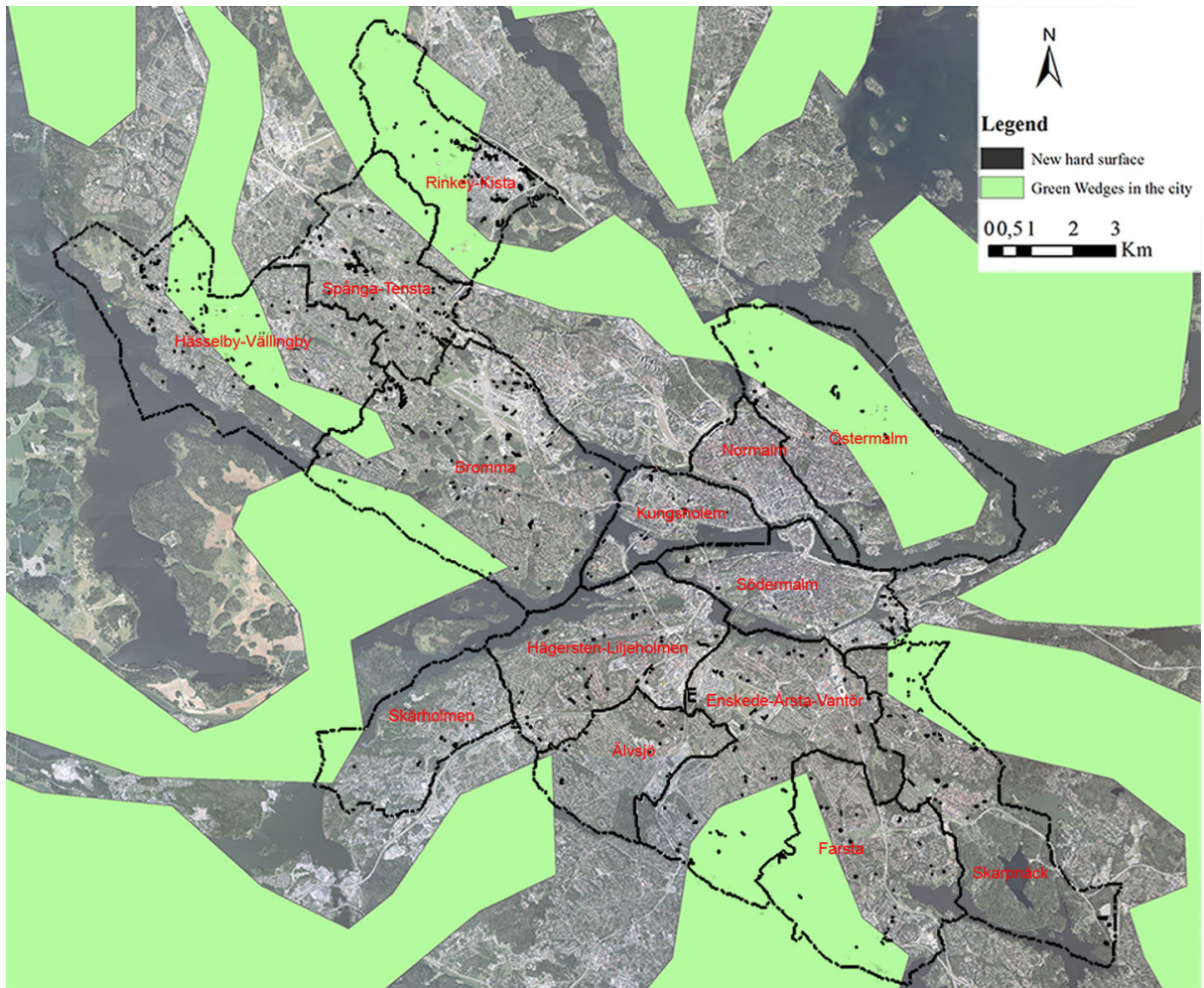

compact city model aimed save energy and resources. Howeer, densification brings along more landscape fragmentation, as well as habitat and recreational green areas loss (Tratalos et al. 2007). Under these conditions an urban green network approach to improve landscape connectivity in densified city areas becomes a pertinent priority in research and planning practice.

\section{Results}

\section{Respective ideal green networks for three indicator species}

By carrying out the LCP analysis in ArcMap, 'ideal' green network maps for the three indicator species were generated. These maps represent the effective paths-connections for wildlife movement of crested tit and common toad, and citizen's connection to nature. Insight into these connections can be an important foundation for planning and design. Taking into consideration the different cost values we propose three separate maps of ideal green networks (Fig. 7).

Figure 7a shows the most cost-saving paths for crested tit and may potentially be relevant for other local birds as well. There are 1711 corridors varying from 0.9 to $36.8 \mathrm{~km}$ in length, $26,537 \mathrm{~km}$ in total. This network allows crested tit to disperse with less resistance among different habitats. Therefore these corridors should be prioritized for conservation of crested tit and similar species as well. The most effective green network paths are distributed in and around the south-eastern part of the city - the Royal National City Park, where crucial habitats are located, such as forest and parks with oak trees. Starting from these important nodes, the LCP corridors travel across residential neighbourhoods with intensively built areas to downtown, connecting the entire city. However, several links pass through the big water barrier of Lake Mälaren.

Figure $7 \mathrm{~b}$ indicates the ideal green network for common toad and possible other amphibians. It contains 1711 corridors which cover $22,249 \mathrm{~km}$, with single length of a corridor ranging from 0.9 to $26.3 \mathrm{~km}$. These corridors were generated to examine the connectivity needs of toads and possible local amphibians and their conservation. Most paths follow the river, bogs and forests in the Royal National City Park, as well as locations in the north-western and north-eastern parts of Stockholm. Ideal green network maps for crested tit and common toad show somewhat similar pattern: intense network paths are connecting the City Park to the north-west part of the city. Some paths are crossing water bodies when necessary.

Figure 7c illustrates local human dwellers' opportunities of recreation to have effective connectivity to green-blue spaces in Stockholm. This map consists of 1711 corridors $(22,138 \mathrm{~km}$ in total) ranging from 0.8 to $33.5 \mathrm{~km}$ in length. This map demonstrates a more even distributed network within the whole city. The cost-saving corridors always run along roads, squares and other open spaces, 


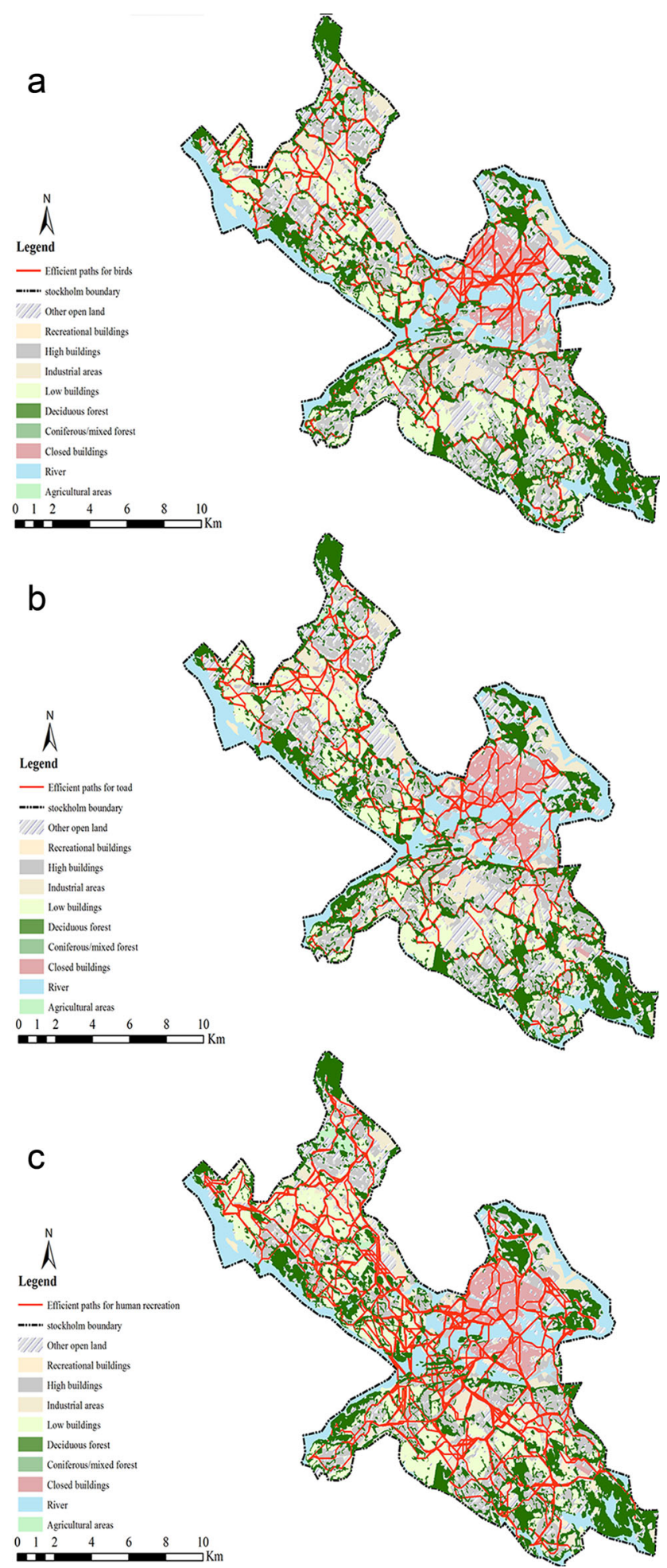

Fig. 7 The cost-efficient green networks for crested tit (a), common toad (b) and human recreation(c)

targeting areas of high recreational value or places that offer contact with nature. Remarkably dense paths are located on the both sides of Lake Mälaren, where places highly preferred by residents in Stockholm are located.

\section{Comprehensive green network and operational priority of improvement}

Our main goal has been to develop a comprehensive green network plan which can combine multiple essential parameters. Both ecological and social requirements, wildlife and human recreation should be taken into consideration in integral green network map. However, for suggesting a comprehensive green networks plan it is problematic to just merge the three separate ideal maps presented in the previous section as every map contains 1711 paths and 5133 corridors in total although some of the paths in these three maps share the same routes (Fig. 8). In Fig. 8 high and medium level density of effective corridors are shown. These areas are going to be crucial dispersal zones for wildlife and humans, as these will help in more effectively connecting different parts of Stockholm. It is clear to see that ideal paths of the highest value link the Royal National City Park in the north-eastern part with north-western and southern part of the city.

When comparing our data with current land use conditions (see background map in Fig. 8), the lack of important green networks in some areas can be clearly seen. They are specifically needed for improvement of connectivity, and this is especially the case for two corridors that can link up the Royal National City Park in the north-eastern part of Stockholm. As one of the most crucial large habitat areas in the city, the National City Park provides a variety of ecosystem services (Löfvenhaft et al. 2004). Thus the linkage between this City Park and the rest of city becomes extremely important. From our density analysis of the green network map we suggest two potential paths which are located on two sides of the park. One path can go from the upper north part of the National Park all along the densely built places in the downtown area until it meets the green wedges in the western part of the city (through Bromma to Rinkeby-Kista and Hässelby-Vällingby districts, connecting the green wedges in these areas). The other path starts from the lower south side of the Park and extends across the water body trying to converge all of the green wedges in the southern part of Stockholm (through Enskede-Årsta-Vantör to Farsta, and to Hägersten-Liljeholmen and Skärholmen districts, meeting the green wedges as well). These two corridors passing through compact infrastructures in the city centre will allow for sufficient migration to important habitat patches.

\section{Localized design of green network in Hjorthagen}

Zooming in to the neighbourhood of Hjorthagen in Norra Djurgårdsstaden, we justify effective corridors by offering a LCP model. After recalculation of LCP and line density through ArcGIS we merged the two separate effective corridors into one vector layer. Since optimal routes for crested tit and human recreation are quite close in location, combining 
Fig. 8 Suggested two parts of green corridors for the city of Stockholm

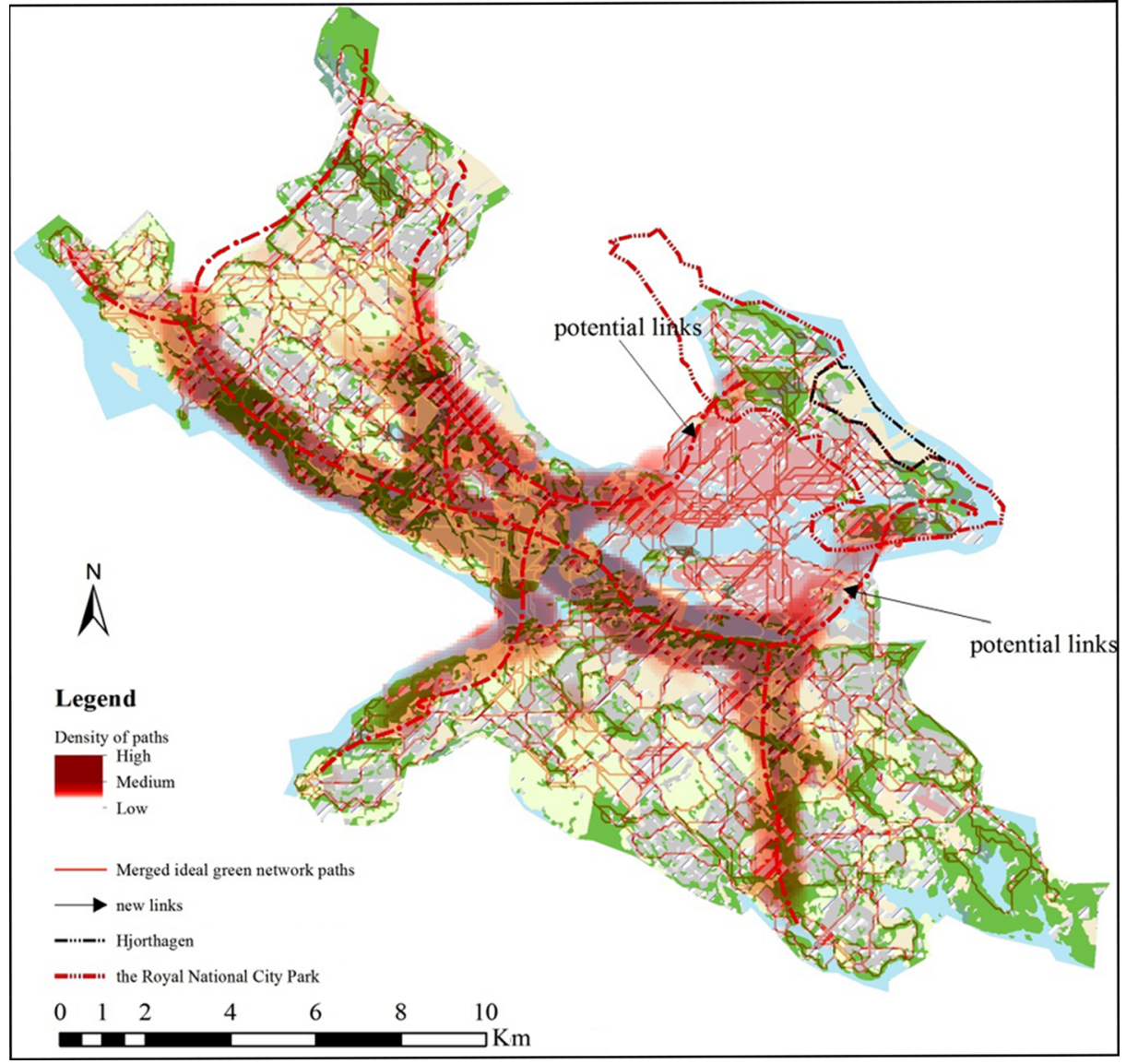

these paths in consideration of construction expenses. The length of offered corridors varies from 196 to $566 \mathrm{~m}$. These two locations of ideal paths-corridors can tie together current habitat patches and green-blue spaces with developed areas. Based on this map we can offer suggestions for potential improvement of the local green network (Fig. 9a). We suggest leaving space for these two corridors in order to link current habitat patches in Hjorthagen to its neighbouring National
City Park since they incorporate different wildlife habitats and water bodies and should be prioritized by municipal planners. One possible street greening plan integrating all three layers of green networks can be proposed, taking into account the three user groups (Fig. 9b). Linking up small streams and ponds in street greening balances the requirements of three different species, and the common toad in particular. As a result of the additional street greening with small ponds in
Fig. 9 Suggested new links between Hjorthagen and the Royal National City Park (a) and possible design of road greening integrating green and blue spaces in densifying areas (b)
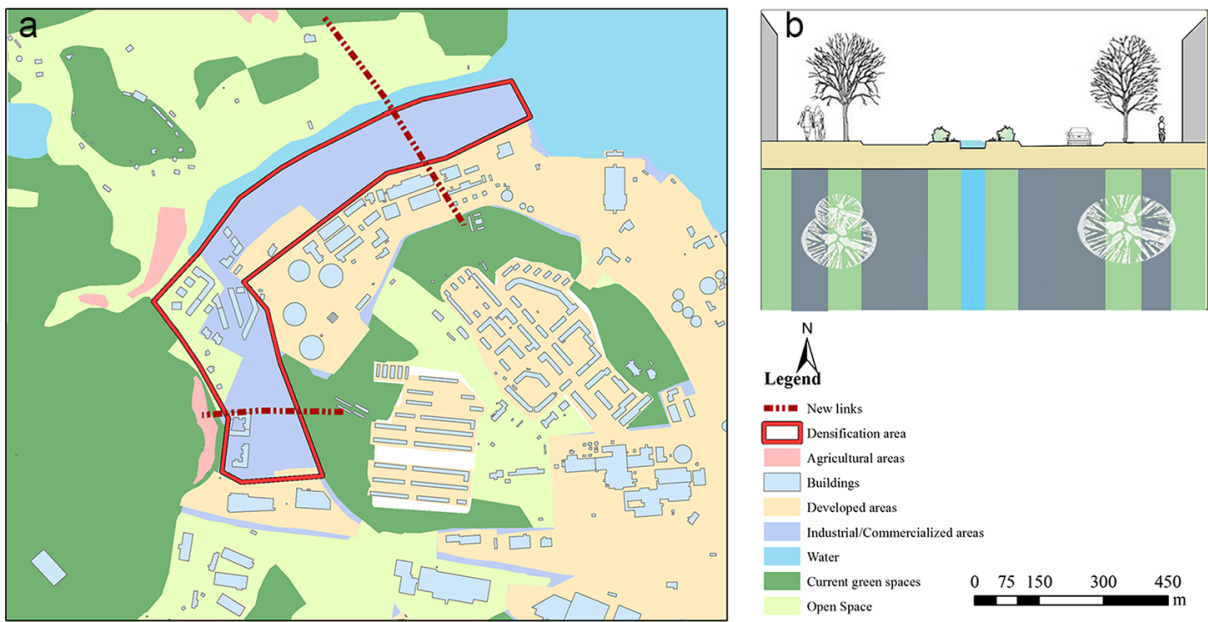
the middle, the potential dispersal probability and net production would increase, as well as the dispersal flux over a larger region.

\section{Discussion}

\section{Green network and network nodes}

This study has confirmed that graph theory is a useful method in support of green-blue spaces planning, as also discussed by e.g. Zetterberg et al. (2010), Teng et al. (2011), Kong et al. (2010), and others. Its network analysis framework in combination with the corresponding spatial extents of the city can offer an integral approach to planning. In this paper we highlighted that different layers of green-blue spaces play different roles. Linear river and transport greening are regarded as links/barriers for the dispersal of (most) species. Green spaces are usually habitats that used by wildlife for living and reproduction. All of these spaces are also used and perceived by humans. The three layers of green-blue spaces offer indispensable values for wildlife and people, and combining these three layers can assist in the creation of integrated green networks.

One of the major issues of the visualizing network approach in green-blue space planning is choosing nodes. Nodes can then be the habitat patches in the green space layers that provide important functions of wildlife living and reproduction, or they can be fragile patches that need to be protected and preserved in front of urban densification and city's development, or they also can be preferred sites for human recreation, contact with nature, etc. How to integrate both ecological and social functions of nodes leads to biotope and sociotope maps, since they provide valuable references on current habitat patches in both perspectives. In order to propose a detailed integration framework of green networks, this paper selected node sources overlapping in two maps since both ecological and social value properties are taken into consideration as the comprehensive planning context. Although one possible issue concerns the conflict of habitats between human and wildlife needs, in the 'real' city environment both groups live and share the habitats. Therefore, identifying their locations as fulfilling both perspectives is crucial for dealing with complex urban ecosystems.

Selection of nodes also concerns network users for which species are proposed to use the graphic network. It relates to species indicators as a result of different criteria, such as focal species, umbrella or endangered species, and so forth. In all, 596 habitats were selected as important nodes for further analysis in Stockholm (Fig. 5b). Suggested maps also show potentially crucial habitats that are already used by wildlife and human. For example we identified several patches in densely built downtown - the closed construction areas (Fig. 5a).
These patches are located in the dense buildings in the city core and isolated from the rest of habitats in the city, but they provide substantial social and ecological values to the whole city. Hence, although no habitat expansion can be realized because of special regulations in this area, understanding their importance and preservation and protection is important.

\section{Cost distance and least-cost-path analysis}

Apart from nodes selection, the LCP analysis needs another layer, namely that of the cost raster. The latter contains the different friction costs of movement that across each cell. Knappen (1992) first proposed using the relative number to decide the cost of values response to patch accessibility based on simulated dispersers. Some researchers have applied a similar way of simplifying the decision of cost values with different variables (Adriaensen et al. 2003; Graham and Marvin 2001; Teng et al. 2011), for example the transitions per day under constant energy constraints and prediction of species' presence/absence in the proximity of source patches. A variety of factors can affect the dedicated cost values, such as land use, vegetation cover, human activities, elevation, etc. The more elements considered the more accurate or comprehensive cost values can be reached. Setting cost through the LCP model is not only a valuable way to consider ecological and social aspects but also integrates economic feasibility into sustainable green-blue spaces planning. In the present study relative energy expenditure was used to decide a range of costs according to species indicators, including three main characters (land use, slope and human disturbance) to decide specific costs and quality weight. Then the final costs value could be set for the LCP analysis and could be achieved by calculating the most effective routes between any other two nodes crossing any possibility of cost pixel.

Although the LCP model represents a potential method for development of green-blue space planning on the bases of current land use, there is still a problem related to the cost assumption of least cost - whether the plants, animals and human choose to use the ideal paths. Literally low-cost corridors of the landscape for an organism would be the optimal movement routes, but for particular species this does not always apply since they cannot use the effective paths for their movement. This calls for further research on better models of actual and ideal organism migration routes as well as the corresponding spatial extents of the connectivity zones.

\section{Operational improvement potentials}

Another issue of using graph network analysis for green-blue spaces planning is to call for improvement potentials for movement facilitation. One of the major advantages of the graph network approach is the convenience of zooming in and out between city and neighbourhood scale while using 
the same approach and model. The proposed green network framework and its test in Stockholm demonstrate how to improve landscape connections in response to the current structural complexity. In this paper we used the LCP model to identify the ideal green network for different species as well as the overall density analysis. This aimed to generate a network intensity map that allows for planning prioritisation. However, this should be integrated with the specific context of cities. For example, this paper tested the framework in one of the greenest cities in Europe - Stockholm. But as a result of its current spatial planning strategy, with a Green Wedges approach at the regional scale, the proposed green corridors are dedicated to enhance landscape connectivity at the city level on the one side, and link the connection between city to regional level on the other. Zooming in on the local neighbourhood scale requires differed strategies for each particular case. At the local scale two corridors and street greening plan were suggested for linking local and neighbouring habitats which are at the moment are separated by built areas. However, proposed suggestions will have to be treated within their respective local contexts, such as planning priorities and research questions.

Our results reveal how multiple functions can be integrated properly into an operational network plan. Having said this, more research is needed on suitable development without substantial impact on biodiversity and ecosystem services. One potential lies in looking at effective green network routes. The LCP model could provide an accessible way of connecting habitat patches as a well-linked network. Leaving spaces for effective corridors in dense areas is extremely important. This links to another potential area of study looking into network resilience when nodes are removed and its influences on the network. As for green network paths, the question matters on how these connectivity zones would be realized and how wide the paths should be for serving as corridors-connectors.

\section{Weaknesses}

Ecological influxes into physical planning and design on the regional, city and local scales are quite complex processes which are not always addressed. For example the surrounding nature of the Stockholm city, addressed in regional planning, is an important provider of ecosystem services and component of larger-scaled green networks. This calls for future studies that integrate Stockholm as well as other municipalities into a wider range of green network analysis. More attention should be given to regional planning approaches for ecological structures which can place neighbouring land and water into a regional context, after all species move not only within the city but also to and within neighbouring areas. Another possible study in the following step would select specific plant as species indicators as well. For example investigating possible dispersals for selected seeds of trees, shrubs or grasses. But this paper only touch the potential that with the migration of bird and amphibian, some plant species would be spread correspondingly.

\section{Conclusion}

This research has looked at physical green-blue spaces extents by applying visualized graph theory. It has illustrated how green networks can be expanded as a multiplefunctioned framework that transfers between different scales. Based on our experiences from testing the approach in Stockholm, the lest-cost-path analysis could be a valid way of providing references for city planners in other cities.

In the process of network visualization and analysis, biotope and sociotope maps were used to fulfil both ecological and social needs of nodes selection. Cost distance and the LCP were chosen for looking for ideal recommendation of network paths-connection in the future. Based on this, improvement suggestions can be proposed in response to current isolated landscapes and the desire to create optimal green networks. Yet several questions need to be further explored. The first concern is more tests (case studies) of green network framework. It does not suffice to test a framework only in one case to evaluate its merits. Thus more tests will be necessary especially those are in different spatial extents, topography and city development patterns. In future research we intend to apply the framework in more cities to check its operation ability and adjustment possibility. Additionally optimizing the analysing tool never ends, so as to green network framework and the LCP model. Crucial steps in the model - nodes and species selection, cost distance and LCP analysis - can still be optimized further. For example, this research only considered mostly-used green spaces from sociotope map. Aesthetic, cultural or educational values could also be integrated into the comprehensive planning. Different criteria of habitat and network users' selection will definitely lead to distinguished potential corridors and improvement strategies. But zooming in and out between scales would be a major advantage in discussing the planning and design of green network.

Acknowledgements This work was supported by the China Scholarship Council under Grant number 20126300191. The authors would like to thank Ulrika Egerö and Gunilla Hjorth from Stockholm Municipality for assisting with biotope and ecological information, Alexander Ståhle for supporting the work with sociotope maps, Professor Emeritus Clas Florgård for valuable suggestions on applying the cost-distance model, and Anders Larsolle for constructive technical assisstance. We also appreciate the constructive feedbacks from two anonymous reviewers. 
Open Access This article is distributed under the terms of the Creative Commons Attribution 4.0 International License (http:// creativecommons.org/licenses/by/4.0/), which permits unrestricted use, distribution, and reproduction in any medium, provided you give appropriate credit to the original author(s) and the source, provide a link to the Creative Commons license, and indicate if changes were made.

\section{References}

Adriaensen F, Chardon JP, De Blust G, Swinnen E, Villalba S, Gulinck H, Matthysen E (2003) The application of 'least-cost' modelling as a functional landscape model. Landsc Urban Plan 64:233-247

Aldous JM, Wilson RJ (2000) Graphs and applications: An introductory approach, 4th print, Chap2 edn. Athenaeum Press, Nottingham

Barbosa O, Tratalos JA, Armsworth PR, Davies RG, Fuller RA, Johnson P, Gaston KJ (2007) Who benefits from access to green space? A case study from Sheffield, UK. Landsc Urban Plan 83:187-195

Billeter R, Liira J, Bailey D, Bugter R, Arens P, Augenstein I, Aviron S, Baudry J, Bukacek R, Burel F (2008) Indicators for biodiversity in agricultural landscapes: a pan-European study. J Appl Ecol 45(1): $141-150$

Bunn AG, Urban DL, Keitt T (2000) Landscape connectivity: a conservation application of graph theory. J Environ Manag 59:265-278

Caro T (2010) Conservation by proxy: indicator, umbrella, keystone, flagship, and other surrogate species. Island Press, Washington D.C

Chapin FS III, Zavaleta ES, Eviner VT, Naylor RL, Vitousek PM, Reynolds HL, Hooper DU, Lavorel S, Sala OE, Hobbie SE (2000) Consequences of changing biodiversity. Nature 405:234-242

Collinge SK (1996) Ecological consequences of habitat fragmentation: implications for landscape architecture and planning. Landsc Urban Plan 36:59-77

Cook EA (2002) Landscape structure indices for assessing urban ecological networks. Landsc Urban Plan 58:269-280

Cook EA, Lier HV (1994) Landscape planning and ecological networks: an introduction. In: Cook E, Lier HV (eds) Landscape planning and ecological network. Elsevier, Amsterdam, pp 1-4

Forman R, Godron M (1986) Landscape ecology. Wiley, New York

Gothnier M, Hjorth G, Östergård S (1999) Rapport från Artarken: Stockholms artdata-arkiv. Miljöförvaltningen, 146 (In Swedish)

Graham S, Marvin S (2001) Splintering urbanism: networked infrastructures, technological mobilities and the urban condition. Routledge, London

Hoffmeister TS, Vet LE, Biere A, Holsinger K, Filser J (2005) Ecological and evolutionary consequences of biological invasion and habitat fragmentation. Ecosystems 8:657-667

Knappen J (1992) Changing the appearance of math. EuroTEX 92. In: Zlatuška J (ed) Tex conference 92, proceedings of the 7th European TEX conference, 14-18 September 1992. Prague, Czechoslovakia, pp 212-216

Kong F, Nakagoshi N (2006) Spatial-temporal gradient analysis of urban green spaces in Jinan, China. Landsc Urban Plan 78:147-164

Kong F, Yin H, Nakagoshi N, Zong Y (2010) Urban green space network development for biodiversity conservation: identification based on graph theory and gravity modeling. Landsc Urban Plan 95:16-27

Löfvenhaft K, Runborg S, Sjögren-Gulve P (2004) Biotope patterns and amphibian distribution as assessment tools in urban landscape planning. Landsc Urban Plan 68:403-427

Luttik J (2000) The value of trees, water and open space as reflected by house prices in the Netherlands. Landsc Urban Plan 48:161-167

McPherson EG (1992) Accounting for benefits and costs of urban greenspace. Landsc Urban Plan 22:41-51
Merriam G (1984) Connectivity: a fundamental ecological characteristic of landscape pattern. In: Brandt J, Agger P (eds) Methodology in Landscape Ecological Research and Planning, Proceedings of the 1st International Seminar of the International Association for Landscape Ecology, 15-19 October 1984, vol I. Roskilde Universitätsforlag Georuc, Roskilde, pp 5-15

Minor ES, Urban DL (2008) A graph theory framework for evaluating landscape connectivity and conservation planning. Conserv Biol 22: 297-307

Mörtberg U, Zetterberg A, Balfors B (2007a) Landskapsekologisk analys i Stockholms stad: Metodutveckling med groddjur som exempel (Dnr: 2008-011175-216, bilaga 2). Miljöförvaltningen, Stockholms stad, Stockholm (In Swedish)

Mörtberg U, Zetterberg A, Gontier M (2007b) Landskapsekologisk analys i Stockholms stad: Habitatnätverk för eklevande arter och barrskogsarter (Dnr: 2008-011175-216, bilaga 1). Miljöförvaltningen, Stockholms stad, Stockholm (In Swedish)

Qiu L, Gao T, Gunnarsson A, Hammer M, von Bothmer R (2010) A methodological study of biotope mapping in nature conservation. Urban For Urban Green 9:161-166

Rayfield B, Fortin MJ, Fall A (2010) The sensitivity of least-cost habitat graphs to relative cost surface values. Landsc Ecol 25:519-532

Simberloff D (1998) Flagships, umbrellas, and keystones: is singlespecies management passé in the landscape era? Biol Conserv 83: $247-257$

Spangenberg JH (2007) Biodiversity pressure and the driving forces behind. Ecol Econ 61:146-158

Ståhle A (2006) Sociotope mapping: exploring public open space and its multiple use values in urban and landscape planning practice. Nordic Journal of Architectural Research 19:59-71

Stockholm Läns Landsting, RUFS (Regional Development Plan for Stockholm) (2010) http://www.rufs.se/globalassets/d.-rufs-2010 /rufs-2010-planen/rufs10 hela.pdf, 2010:5

Stockholm Stad (2012) Stockholm Stads biotoper: Reviderad databas för Stockholms biotopkarta och övergripande analys av förändringar mellan 1998 och 2009. http://miljobarometern.stockholm. se/content/docs/tema/natur/biotopkarta 2009 publ.pdf, 2012-4608

Sukopp H, Weiler S (1988) Biotope mapping and nature conservation strategies in urban areas of the Federal Republic of Germany. Landsc Urban Plan 15:39-58

Taylor PD, Fahrig L, Henein K, Merriam G (1993) Connectivity is a vital element of landscape structure. Oikos:571-573

Teng MJ, Wu CG, Zhou ZX, Lord E, Zheng ZM (2011) Multipurpose greenway planning for changing cities: a framework integrating priorities and a least-cost path model. Landsc Urban Plan 103:1-14

Tratalos J, Fuller RA, Warren PH, Davies RG, Gaston KJ (2007) Urban form, biodiversity potential and ecosystem services. Landsc Urban Plan 83(4):308-317

Urban D, Keitt T (2001) Landscape connectivity: a graph-theoretic perspective. Ecology 82:1205-1218

Xiu N, Ignatieva M, Konijnendijk C (2016) The challenges of planning and designing of urban green networks in Scandinavian and Chinese cities. Journal of Architecture and Urbanism 40(3):163-176

Zetterberg A (2011) Connecting the dots: network analysis, landscape ecology, and practical application. Dissertation, Royal Institute of Technology, Stockholm

Zetterberg A, Mörtberg UM, Balfors B (2010) Making graph theory operational for landscape ecological assessments, planning, and design. Landsc Urban Plan 95:181-191

Zhang LQ, Wang HZ (2006) Planning an ecological network of Xiamen Island (China) using landscape metrics and network analysis. Landsc Urban Plan 78:449-456 